\title{
Clindamycin Resistance in PVL Positive Isolates of Staphylococcus aureus, Belgaum, North Karnataka (India)
}

\author{
Harleen Kaur*1, Harbhajan $\operatorname{Kaur}^{1}$ \\ Faculty of Life Sciences, Punjabi University, Patiala-147002, Punjab, India \\ Faculty of Life Sciences, Punjabi University, Patiala-147002, Punjab, India
}

\begin{abstract}
The widespread use of Macrolide Lincosamide Streptogramin B (MLSB) antibiotics has led to an increase in the resistant strains. Although Clindamycin is effective against MRSA but its use in the presence of Erythromycin can lead to induction of cross-resistance among members of the MLSB group which could limit the effectiveness of this drug. Furthermore, at times, some strains are also harbored with PVL genes which are encoded by two contiguous and co-transcribed genes viz., lukF-PV and lukS-PV. The results of a study conducted to find the prevalence of inducible Clindamycin resistance in PVL positive isolates of Staphylococcus aureus from Belgaum, Karnataka, India. Method: More than 120 isolates of S.aureus were collected from hospital in Belgaum during the period 2010-2012, out of which, 72 isolates confirming S.aureus status were kept for further study at RMRC (ICMR), Belgaum. They were characterized as resistant/sensitive using various conventional, molecular and automated techniques. PVL genes LukS and LukF in these strains were detected by PCR. Phenotypic inducible resistance to clindamycin was detected by Double Disk Diffusion test. Result: Out of 72 isolates, 46 were MRSA and 26 were MSSA. In all, 50 isolates (69.44\%) showed the presence of PVL genes. Out of these, 14 PVL positive S. aureus isolates (26.38\%) showed iMLSB phenotype which included 13 MRSA and 1 MSSA. Conclusion- The cause of concern is the 13 isolates which are MRSA, PVL positive and show inducible clindamycin resistance. Such a combination can be a treatment challenge to the clinicians who are left with very few options.
\end{abstract}

Keywords: - Macrolide Lincosamide Streptogramin B (MLSB), PVL genes, PCR, iMLSB, cMLSB, Vitek 2 compact automated system

\section{INTRODUCTION}

Methicillin resistant Staphylococcus aureus (MRSA) is a major cause of nosocomial and community acquired infections [1]. Macrolide Lincosamide Streptogramin B (MLSB) antibiotics are frequently being used to treat such infections. However, their widespread use has led to an increase in the number of Staphylococcus strains resistant to MLSB antibiotics [2]. Clindamycin, a Lincosamide antibiotic, is among the limited choice of antimicrobials effective against MRSA and has long been an option for treating both MSSA and MRSA infections. However, there is concern about use of this antibiotic in the presence of Erythromycin resistance because of the possibility of induction of cross-resistance among members of the Macrolide, Lincosamide and Streptogramin B (MLSB group) which could limit the effectiveness of this drug [3].

PVL proteins, one of the most important and extensively investigated proteins, belong to the family of synergohymenotropic toxins [4]. These toxins damage membranes of host defense cells by synergistic action of two non-associated classes of secretory proteins designated as Luk-S and Luk-F, which are encoded by two contiguous and co-transcribed genes viz., lukF-PV and lukS-PV [5] of bacteriophages inserted in the bacterial chromosome. Epidemiological and clinical data [6] provide compelling evidence that the high virulence potential of community acquired MRSA is associated with genes like $l u k F-P V$ and $l u k S-P V(\mathrm{PVL})$, but direct evidence that PVL plays a role in pathogenesis has been limited [7]. PVL is leukotoxic by pore induction for human polymorphonuclear cells and macrophages [8]and its presence in S. aureus appears to be associated with increased disease severity, ranging from cutaneous infection to chronic osteomyelitis and severe necrotizing pneumonia which could be fatal [9]. PVL production has also been linked with furuncles, cutaneous abscess and severe necrotic skin infections in school children [10] and in certain communities [11].

Data describing MLSB prevalence or clinical predictors of the presence of inducible MLSB (iMLSB) among PVL positive S.aureus isolates is limited in India. In the present study, we aimed to characterize iMLSB resistance in isolates of Staphylococcus aureus isolates, both MRSA and MSSA, taken randomly at hospitals in Belgaum catering to patients from North Karnataka, Southern Maharashtra and Goa. Indoor as well as outdoor patients were included together in the study with the intention to cover cases of both community-acquired as well as hospital-acquired infections. 


\section{MATERIAL AND METHODS}

More than 120 isolates of S.aureus were collected after obtaining due ethical clearance from microbiology laboratory of a hospital in Belgaum that receives samples from various outdoor and indoor patient departments, out of which 72 isolates confirming S.aureus status were kept for the further research study during the period 2010-2012.

\section{(A) Collection and Identification:}

S.aureus isolated from various clinical samples at microbiology departments of hospitals included in this study were collected and their identities were reconfirmed by standard microbiological tests viz most notably the gram stain, catalase, coagulase tests, beta haemolysis and manitol fermentation (Note: Isolates absolute positive for above five tests were kept for the study and rest were left aside. Some isolates showing negative for mannitol fermentation but positive for other four tests were also not included in study).

\section{(B) Detection and confirmation of MRSA:}

All isolates were subjected to phenotypic Cefoxitin, 30 $\mu \mathrm{g}$ (Hi-Media, India) following CLSI guidelines [12] for disc-diffusion testing. The zone of inhibition was measured after $24 \mathrm{hrs}$ incubation at $37^{\circ} \mathrm{C}$ and isolates were labeled as susceptible at $\geq 22 \mathrm{~mm}$ and resistant at $\leq 21 \mathrm{~mm}$ zone of inhibition. ATCC 43300 and ATCC 25923 were included in every batch as standard strains for MRSA and MSSA respectively.

Confirmation of MRSA was done by carrying out Multiplex PCR for the detection of $m e c A$ and femB genes which is a gold standard for confirming the identity of MRSA [13]. DNA was extracted from overnight cultures of S.aureus by CTAB-NaCl method [14] and was checked for quality and quantity using Nanodrop Spectrophotometer at $260 / 280 \mathrm{~nm}$ as well as visually by horizontal gel electrophoresis in $1 \%$ agarose. $1 \mu$ lcontaining $60 \mathrm{ng}$ of the extracted DNA was added to $24 \mu \mathrm{l}$ of PCR amplification mix consisting of $16 \mu \mathrm{l}$ of double distilled autoclaved water, $2.5 \mu$ lof $10 \mathrm{X}$ Taq buffer (Tris with $15 \mathrm{mM} \mathrm{MgCl}$ ), $1 \mu$ lof $2.5 \mathrm{mM}$ dNTP mix (Merck, India), $0.5 \mu \mathrm{l}$ of $3 \mathrm{U}$ Taq polymerase (Merck, India), and0.5mM of each primer given in the Table: I. Amplifications were carried out using thermal cycler with PCR conditions that consisted of 30 cycles of denaturation at $94^{\circ} \mathrm{C}$ for $45 \mathrm{~s}$, annealing at $50^{\circ} \mathrm{C}$ for $45 \mathrm{~s}$ and extension at $72^{\circ} \mathrm{C}$ for $1 \mathrm{~min}$ with a final extension at $72^{\circ} \mathrm{C}$ for $2 \mathrm{~min}$. The PCR products were subjected to agarose gel electrophoresis using gel red dye (Biogenei, Bangalore) and documented.

\section{(C) Detection of luk-F (PV) and luk-S (PV) genes:}

$1 \mu \mathrm{l}$ containing $60 \mathrm{ng}$ of extracted S.aureus DNA was added to $24 \mu$ l of PCR amplification mix consisting of $18 \mu \mathrm{l}$ of double distilled autoclaved water, $2.5 \mu$ l of $10 \mathrm{X}$ Taq buffer (Tris with $15 \mathrm{mM} \mathrm{MgCl}_{2}$ ), $1 \mu$ of 2.5 $\mathrm{mM}$ dNTP mix (Merck, India), $0.5 \mu \mathrm{l}$ of $3 \mathrm{U}$ Taq polymerase (Merck, India) and $0.5 \mathrm{mM}$ of each primer given in the Table: I. Amplifications were carried out using thermal cycler with PCR conditions that consisted of initial denaturation at $94^{\circ} \mathrm{C}$ for $99 \mathrm{sec}$ followed by 10 cycles of denaturation at $94^{\circ} \mathrm{C}$ for $60 \mathrm{~s}$, annealing at $55^{\circ} \mathrm{C}$ for $60 \mathrm{~s}$ and extension at $72^{\circ} \mathrm{C}$ for $90 \mathrm{sec}$ followed by 25 cycles of denaturation at $94^{\circ} \mathrm{C}$ for $60 \mathrm{~s}$, annealing at $50^{\circ} \mathrm{C}$ for 60 $\mathrm{s}$ and extension at $72^{\circ} \mathrm{C}$ for $90 \mathrm{~s}$ with final extension at $72^{\circ} \mathrm{C}$ for $5 \mathrm{~min}$. The PCR products were electrophoresed in $1 \%$ agarose gel and documented.

\section{(D) Phenotypic inducible resistance to clindamycin by Double Disk Diffusion test:}

Isolates were placed on a Muller Hinton agar as per [12]. Clindamycin and Erythromycin disks, containing $2 \mu \mathrm{g}$ and $15 \mu \mathrm{g}$ each respectively were placed in the center of the plate separated by a distance of 15 $\mathrm{cm}$ between the edges. Plates were incubated at $37^{\circ} \mathrm{C}$ for $24 \mathrm{hr}$. Inducible resistance to Clindamycin was defined as blunting of the clear circular area of no growth around the Clindamycin disk on the side adjacent to the Erythromycin disk and was designated as D - test positive. Absence of a blunted zone of inhibition was designated as D - test negative. Four different phenotypes were interpreted as follows $[15,16]$.

1. Sensitive phenotype (S):S.aureus isolates showing sensitivity to both Clindamycin (Zone size> $21 \mathrm{~mm}$ ) and Erythromycin (Zone size> 23mm).

2. Constitutive MLSB phenotype(cMLSB):S.aureus isolates showing resistance to both Erythromycin (Zone size $<13 \mathrm{~mm}$ ) and Clindamycin (Zone size $<14 \mathrm{~mm}$ ) with circular shape of zone of inhibition if any around Clindamycin.

3. Moderately Sensitive phenotype (MS): S.aureus isolates showing resistance to Erythromycin (Zone size $<13 \mathrm{~mm}$ ) and sensitivity to Clindamycin with a circular zone of inhibition (Zone size > 21mm) around Clindamycin disc (D-negative).

4. Inducible MLSB phenotype(iMLSB):S.aureus isolates showing resistance to Erythromycin (zone size $<13 \mathrm{~mm}$ ) and sensitivity to Clindamycin giving D - shaped zone of inhibition (Zone size>21mm) around Clindamycin disc (D-positive). 


\section{RESULTS}

All S.aureus isolates were subjected to conventional tests and PCR based mecA and femB genes detection to confirm their identity and to detect their sensitivity to Methicillin. Out of 72 isolates, 46 were MRSA and 26 were MSSA (Table: II) by conventional and PCR based analysis any discrepancies were cleared by Vitek 2 compact automated system (BioMerieux, France. Software version: 05.02) as referred in our paper [17].

The results of PCR based detection of $l u k F$-PV and $l u k S$-P are shown in Table: II. Out of 72 isolates, 50 isolates (69.44\%) showed the presence of PVL genes which included 36 MRSA and 14 MSSA. 22 isolates $(30.56 \%)$ showed the absence of PVL genes which included 10 MRSA and 12 MSSA.

All the 72 isolates were put for MLSB phenotype detection by Double Disc Diffusion method using Erythromycin $15 \mu \mathrm{g}$ and Clindamycin $2 \mu \mathrm{g}$ and results are shown in the Table : III. The results showed 28 isolates (38.88\%) to be Sensitive phenotype (S) and 44 to be resistant to Erythromycin. Out of 44 resistant isolates, 25 isolates (34.72\%) were found to be Moderately Sensitive (MS), 19 isolates (26.39\%) to be inducible $\mathrm{MLS}_{\mathrm{B}}$ phenotype (iMLSB) and none to be constitutiveMLSB phenotype (cMLSB).

Inducible Clindamycin resistance in isolates of Staphylococcus aureus was characterized with respect to Methicillin susceptibility and PVL positivity (Table: IV). Out of 28 Sensitive isolates, 11 were PVL positive MRSA, 8 were PVL positive MSSA, 2 were PVL negative MRSA and 7 were PVL negative MSSA. Out of 25 Moderately Sensitive isolates, 12 were PVL positive MRSA, 5 were PVL positive MSSA, 4 were PVL negative MRSA and 5 were PVL negative MSSA. Out of 19 inducible MLS $_{\mathrm{B}}$ isolates, 13 were PVL positive MRSA, 1 was PVL positive MSSA, 4 were PVL negative MRSA and 1 was PVL negative MSSA.

\section{DISCUSSION}

In the present study, mec $A$ positivity was found in 46 out of 72 isolates $(63.89 \%)$ and 26 showed absence of mec $A$ gene (36.11\%). From India, MRSA prevalence has been reported to be different from different regions, being 17.2\% from Madhya Pradesh [18], 54.5\% from Utter Pradesh [19], 31.8\% from Tamil Naidu [20], 52.23\% from Sikkim [21] and 46\% from Punjab [22]. Alvarez-Uria and Reddy (2012) reported 64.8\% MRSA in community acquired S.aureus and $70.7 \%$ in hospital acquired S.aureus from Bathalapalli, Andhra Pradesh [23].

The prevalence of PVL gene in $S$. aureus has been observed to be very high in present study, being present in 50 out of 72 isolates $(69.4 \%)$. About a decade ago, the prevalence of PVL gene in S. aureus was less than 5\% in France [24]. But now its prevalence is increasing worldwide with reports showing $11.6 \%$ from Singapore, 35\% from Cape Verde Islands, 14.3\% from Bangladesh, 37.6\% from Saudi Arabia [25,26,27,28].

In the present study, 78.2\% of MRSA (36 of 46 MRSA isolates) and 53.8\% of MSSA (14 out of 26 MSSA isolates) were found to be PVL positive. D'Souza et al. (2010) reported 64\% PVL positive MRSA from Mumbai [29]. However, proportion of PVL positive MRSA is comparatively lower in other countries. The higher prevalence of PVL-MRSA as compared to PVL-MSSA in the present study may be due to the overuse of antibiotics in India causing selective pressure for development of resistant strains along with the virulence factor (PVL). Furthermore, although the proportion of PVL-MSSA is comparatively lower than PVL-MRSA but it is not too low to be ignored, and need even more attention because these PVL positive MSSA can in future get converted to MRSA [7]. Aires-de-Sousa et al. (2006) suggested that acquisition of PVL genes from different phages must be of a greater advantage to S.aureus than antibiotic resistance gene [26].

Detection of MLSB phenotype in $72 \mathrm{~S}$. aureus isolates by Double Disc diffusion method showed 25 isolates (34.72\%) to be Moderately Sensitive, 28 (38.89\%) to be Sensitive, 19 (26.39\%) to be iMLSB and none to be cMLSB. Therefore, there was total absence of cMLSB in the region of study as was also reported from Vellore (Tamil Naidu) by Angel et al. (2008) [30]. On the other hand, several reports from other parts of India reveal the presence of both iMLSB and cMLSB such as $24.89 \%$ iMLSB and $18.26 \%$ cMLS $_{\mathrm{B}}$ from Bangalore, Karnataka [31], 21\% iMLSB and 26.5\% cMLSB from Delhi [32], 3.6\% cMLSB and 14.5\% iMLSB [15], $26.43 \%$ cMLSB and 3.57\% iMLSB from Nagpur, Maharashtra [33], 43\% iMLSB and 12\% cMLSB from Varda, Gujrat [34]. In metropolitan cities like Delhi and Bangalore, high percentage of constitutive MLSB resistance has been suggested to be due to crowded settings, population pressure, less hygiene in community as well as hospitals settings or overuse of the drug and conversion of inducible phenotype to constitutive phenotype during treatment $[32,35,31]$. Moreover, Clindamycin resistance rates have been seen to vary with geographic region and Methicillin susceptibility [36,32, 31].

In the present study, 14 PVL positive $S$. aureus isolates $(26.38 \%)$ showed iMLSB phenotype which included 13 MRSA and 1 MSSA. Actually the cause of concern are the 13 PVL positive MRSA isolates which also showed inducible Clindamycin resistance. Such strains can be a treatment challenge to the clinicians because when MRSA strains carry additional resistant genes (genes for Clindamycin or PVL genes), only few therapeutic options are left for treatment. PVL positive patients with prolonged stay in hospitals and after 3 weeks of antibiotic completion can become resistant to Vancomycin or Linezolid and have to be immediately 
put on alternate antibiotics such as Teicoplanin and Rifampicin [37]. Empirical Clindamycin treatment for suspected Staphylococcal infections is not recommended in areas where the proportion of MRSA isolates exceeds $10 \%$ to $15 \%$ [38]. Among Staphylococcal infections due to isolates exhibiting inducible Clindamycin resistance, the risk of treatment failure during Clindamycin therapy is increased when there are high bacterial inoculums [39, 40].

It is, therefore, concluded that patients with PVL positive MRSA infections along with inducible Clindamycin resistance can be a treatment challenge to the clinicians and should be put on antibiotic therapy carefully, so that they should not get resistant to the antibiotic.

\section{ACKNOWLEDGEMENTS}

We are thankful to all the hospitals in (Belgaum) for supporting the study. We also thank Dr. Camilla Rodrigues, P.D. Hinduja National Hospital, Mumbai and Lt.Col. (Dr.) Jai Inder Singh from Millitary Hospital, Belgaum for donating strains and isolates. We would also like to acknowledge Mrs. Nandini Bhatt and for her technical assistance.

Table I: Details of oligonucleotide primers used in PCR.

\begin{tabular}{|c|c|c|c|c|}
\hline Primer & Target gene & Sequence (5'-3') & $\begin{array}{c}\text { Amplicon } \\
\text { size }\end{array}$ & Ref. \\
\hline $\begin{array}{l}\operatorname{mec} \mathrm{A} 1 \\
\operatorname{mec} \mathrm{A} 2\end{array}$ & mec-A & $\begin{array}{l}\text { GTA GAA ATG ACT GAA CGT CCG ATA } \\
\text { A } \\
\text { CCA ATT CCA CAT TGT TTC GGT CTA A }\end{array}$ & $310 \mathrm{bp}$ & [41] \\
\hline $\begin{array}{l}\text { fem B1 } \\
\text { fem B2 }\end{array}$ & fem- $B$ & $\begin{array}{l}\text { TTA CAG AGT TAA CTG TTA CC } \\
\text { ATA CAA ATC CAG CAC GCT CT }\end{array}$ & $651 b p$ & [41] \\
\hline $\begin{array}{l}\text { luk-PV-1 } \\
\text { luk-PV-2 }\end{array}$ & $\begin{array}{l}l u k-S(P V) \text { and } \\
l u k-F(P V)\end{array}$ & $\begin{array}{l}\text { ATC ATT AGG TAA AAT GTC TGG ACA } \\
\text { TGA } \\
\text { GCA TCA AGT GTA TTG GAT AGC AAA } \\
\text { AGC }\end{array}$ & 433bp & [24] \\
\hline
\end{tabular}

Table II. Depicting the frequency of $P V L$ genes in MRSA and MSSA

\begin{tabular}{|c|c|c|}
\hline \multirow{4}{*}{$\begin{array}{c}\text { Total } \\
\text { isolates }(\mathbf{n})= \\
(72)\end{array}$} & \multirow[b]{2}{*}{$\begin{array}{l}\text { MRSA } \\
(46)\end{array}$} & $\begin{array}{c}P V L \text { gene positive } \\
(36)\end{array}$ \\
\hline & & $\begin{array}{c}P V L \text { gene negative } \\
\text { (10) }\end{array}$ \\
\hline & \multirow{2}{*}{$\begin{array}{l}\text { MSSA } \\
(26)\end{array}$} & $\begin{array}{c}P V L \text { gene positive } \\
\text { (14) }\end{array}$ \\
\hline & & $\begin{array}{c}P V L \text { gene negative } \\
\text { (12) }\end{array}$ \\
\hline
\end{tabular}

Table III: Different phenotypes of Clindamycin resistance in S.aureusisolates

\begin{tabular}{|l|l|l|l|l|}
\hline S/N & Susceptibility Pattern & Phenotype & Total & Percentage \\
\hline 1 & ER-S, CL-S & S & 28 & $38.88 \%$ \\
\hline 2 & ER-R, CL-R & cMLS $_{\text {B }}$ & 00 & $00.00 \%$ \\
\hline 3 & ER-R, CL-S; D & MS & 25 & $34.72 \%$ \\
\hline 4 & ER-R, CL-S; D & iMLS $_{\text {B }}$ & 19 & $26.38 \%$ \\
\hline
\end{tabular}

Key Words: ER: Erythromycin, CL: Clindamycin, cMLS $\mathrm{B}_{\mathrm{B}}$ : Constitutive resistance to Clindamycin, iMLS $_{\mathrm{B}}$ :Inducible Clindamycin resistance, MS:Moderately Sensitive, $\mathrm{D}^{-}$: negative double diffusion test, $\mathrm{D}^{+}$: positive double diffusion test, S:Sensitive,R:Resistant 
Clindamycin Resistance in PVL Positive Isolates of Staphylococcus aureus, Belgaum, North

Table IV: Distribution of PVL positive isolates in different $S$. aureusphenotypes of Clindamycin resistance.

\begin{tabular}{|l|l|l|l|l|l|l|}
\hline \multirow{2}{*}{ S.N. } & \multirow{2}{*}{} & & & Phenotype & No. of isolates & \multicolumn{2}{|c|}{ MRSA } & \multicolumn{2}{|c|}{ MSSA } \\
\cline { 4 - 8 } & & & PVL + & PVL- & PVL + & PVL- \\
\hline 1 & $\mathrm{~S}$ & 28 & 11 & 2 & 8 & 7 \\
\hline 2 & cMLS & $\mathbf{0 0}$ & 00 & 00 & 00 & 00 \\
\hline 3 & MS & $\mathbf{2 5}$ & 12 & 4 & 5 & 4 \\
\hline 4 & iMLS & $\mathbf{1 9}$ & $\mathbf{1 3}$ & 4 & $\mathbf{1}$ & 1 \\
\hline & Total & 72 & 36 & 10 & 14 & 12 \\
\hline
\end{tabular}

KeyWords : ER: Erythromycin, CL: Clindamycin, cMLS $_{\mathrm{B}}$ Constitutive resistance to clindamycin, iMLS $\mathrm{B}_{\mathrm{B}}$ Inducible clindamycin resistance, MS:Moderately Sensitive, $\mathrm{D}^{-}$: negative to Double Diffusion test, $\mathrm{D}^{+}$: positive to Double Diffusion test, S: Sensitive, R: Resistant.

\section{REFERENCES}

[1] A.L. Frank, J.F. Marcinak, P.D. Mangat and P.C. Schreckenberger, "Community-acquired methicillin and Clindamycin-susceptible methicillin-resistant Staphylococcus aureus in children," Pediatric. Infect. Dis. J., vol.18, pp. 993-1000,1990.

[2] L. Saiman, M. O'Keefe, P. Graham, F. Wu, B. Said-Salim and B. Kreiswirth, A. LaSala, P.M. Schlievert,. and P. Della-Latta, "Hospital transmission of community-acquired methicillin-resistant Staphylococcus aureus among postpartum women," Clin. Infect. Dis., vol 37, pp. 1313-1319, 2003.

[3] F.M. Hussain, S. Boyle-Varva, C.D. Bethel and R.S., "Daum Currents trend in community-acquired methicillin-resistant Staphylococcus aureus at a tertiary care pediatric facility," Pediatr. Infect. Dis J., vol. 19, pp. 1163-1166, 2000.

[4] G. Supersac, G. Prévost and Y Piémont, "Sequencing of leucocidin R from Staphylococcus aureus P83 suggests that staphylococcal leucocidins and gamma- hemolysin are members of a single, twocomponent family of toxin," Infect Immun, vol. 61, pp. 580-7, 1993.

[5] G.Prevost, B. Cribier, P. Couppié, P. Petiau, G. Supersac, V. Finck-Barbancon, Monteil, H. and Piemont, Y., "Panton-Valentine leucocidin and gamma-hemolysin from Staphylococcus aureus ATCC 49775 are encoded by distinct genetic loci and have different biological activities," Infect. Immun., vol.63, pp. 4121-9, 1995.

[6] F. Vandenesch, T. Naimi, M.C. Enright, G. Lina, G.R. Nimmo, H. Heffernan, N. Liassine, M. Bes, T. Greenland, M.E.Reverdy and J. Etienne, "Community- acquired methicillin-resistant Staphylococcus aureus carrying Panton-Valentine leukocidin genes: world- wide emergence," Emerg Infect Dis vol. 9, pp. 978-84, 2003.

[7] S. Boyle-Vavra and S Daum, "Community-acquired methicillin-resistant Staphylococcus aureus: the role of Panton-Valentine Leukocidin,” Lab Investigation vol 87,pp. 3-9, 2007.

[8] V. Finck-Barbancon, G. Duportail and O. Meunier, D.A., "Colin Pore formation by two-component leukocidin from Staphylococcus aureus within the membrane of human polymorphonuclear leukocytes," Biochem Biophys Acta, vol. 1182, pp. 275-82, 1993.

[9] J.S. Francis, M.C. Doherty, U. Lopatin, C.P. Johnston, G. Sinha and T. Ross, "Severe community-onset pneumonia in healthy adults caused by methicillin-resistant Staphylococcus aureus carrying the Panton-Valentine leukocidin genes," Clin Infect Dis, vol. 40, pp. 100-07, 2005.

[10] K. Boubaker, P.Diebold, D.S. Blanc, F. Vandenesch, G. Praz and G. Dupuis, "Panton-Valentine Leukocidin and Staphyloccoccal Skin Infections in Schoolchildren. Emerg Infect Dis., vol. 10, pp.121-24, 2004.

[11] Centers for Disease Control and Prevention (CDC). Outbreaks of community-associated methicillinresistant Staphylococcus aureus skin infections--Los Angeles County, California, 2002-2003. Morb Mortal Wkly Rep, vol. 52, pp. 88, 2003.

[12] Performance Standards for Antimicrobial Susceptibility Testing (2010) $20^{\text {th }}$ Informational Supplement, Clinical and Laboratory Standards Institute (CLSI) M100-S20: Vol. 30, No. 1. Wayne, PA: Clinical and Laboratory Standards Institute.

[13] S. Unal, J. Hoskins, J.E Flokowitsch, C.Y. Wu, D.A. Preston, and P.L Skatrud, "Detection of Methicillin 
resistant Staphylococcus aureus by polymerase chain reaction," Journal of ClinicalMicrobiology, vol30(7), pp.1685, 1992.

[14] F.M. Ausubel, R. Brent, R. Kingston, D.E. Moore, Seidman and J.A. Smith, Short Protocols in Molecular Biology, 4th edn. John Wiley and Sons Inc. 1999, New York.

[15] V. Deotale, D.K. Mediratta and U. Raut, "Inducible clin-damycin resistance in Staphylococcus aureus isolated from clinical samples," Indain J Med Microbiology, vol 28 (2), pp 124-126, 2010.

[16] W.E. Kloos and T.L. Banerman, Staphlococcus and Micro-coccus, Chapter22. In: Manual of clinical microbiol-ogy. 7th ed. Murray PR, Baron EJ, Pfaller MA, Tenoer FC, Yolken RH, editors. Washington DC. ASM Press; 1999: 264-282.

[17] H. Kaur, A. Saini, S. Purwar, H. Kaur, S.G. Kardesai, S. D. Kholkute and S. Roy "Susceptibility testing and resistance phenotypic detection in Staphylococcus aureus by conventional and molecular methods: Importance of automated (Vitek 2) system," International Journal of Engineering Research and Development, vol. 3(10), pp.68-74, 2012.

[18] S. Anupurba, M.R Sen, G. Nath, B.M Sharma, A.K Gulati,. and T.M. Mohapatra, "Prevalence of Methicillin resistant Staphylococcus aureus in a tertiary referral hospital in eastern Uttar Pradesh," Indian Journal of Medical Microbiology, vol.21(1), pp. 49-51, 2003.

[19] S.Verma, S.Joshi, V.Chiunis, N. Hemwani and D. Chitnis, "Growing problem of Methicillin resistant staphylococci-Indian scenario,” Indian Journal of Medical Microbiology, vol. 54(12), pp. 535-540, 2000.

[20] K. Rajaduraipandi, K.R. Mani, K. Pannerselvam, M. Mani, M. Bhaskar, and P. Manikandan, "Prevelance and antimicrobial susceptibility pattern of Methicillin resistant Staphylococcus aureus: a multicentred study," Indian Journal of Medical Microbiology, vol. 24(1), pp. 34-38, 2006.

[21] D.C. Tsering, R. Pal, and S. Kar, "Methicillin-resistant Staphylococcus aureus: Prevalence and current susceptibility pattern in Sikkim,” Journal of Global Infectious Diseases, vol. 3, pp. 9-13, 2011.

[22] S. Arora, P. Devi, U. Arora, and B. Devi, "Prevelance of Methicillin resistance Staphylococcus aureus (MRSA) in tertiary care hospital in Northern India," Journal of Laboratory Physicians, vol. 2(2), pp.78$81,2010$.

[23] G. Alvarez-Uria, and R. Reddy, "Prevalence and Antibiotic Susceptibility of Community-Associated Methicillin-Resistant Staphylococcus aureus in a Rural Area of India: Is MRSA replacing MethicillinSusceptible Staphylococcus aureus in the Community? ISRN Dermatology Article doi: 10.5402/2012/248951, 2012.

[24] G. Lina, Y. Piemont, F. Godail-Gamot, M. Bes, M.O. Peter, V. Gauduchon, F. Vandenesch, and J. Etienne, "Involvement of Panton-Valentine leukocidin-producing Staphylococcus aureus in primary skin infections and pneumonia." Clinical Infectious Diseases, vol. 29, pp. 1128-1132, 1999.

[25] L.Y. Hsu, T.H. Koh, A. Kurup, J.Low, M.P.Chlebicki and B. H. Tan, "High incidence of PantonValentine leukocidin-producing Staphylococcus aureus in a tertiary care public hospital in Singapore," Clin infect. dis.,vol.40(3), pp.486-489, 2005.

[26] M. Aires-de-Sousa, T. Conceicao, and H. De lencastre, "Unusually High Prevalence of Nosocomial Panton-Valentine Leukocidin-Positive Staphylococcus aureus Isolates in Cape Verde Islands," Journal of Clinical Microbiology, vol. 44(10), pp. 3790-3793. 2006.

[27] S. Afroz, N. Kobayashi, S. Nagashima, M.M.Alam, A.B. Hossain, M.A Rahman, M..R. Islam, A.B. Lutfor, N. Muazzam, M.A.Khan, S.K. Paul, A.K. Shamsuzzaman, M.C. Mahmud, A.K. Musa and M.A. Hossain, "Genetic characterization of Staphylococcus aureus isolates carrying Panton-Valentine leukocidin genes in Bangladesh,” Japanese Journal of Infecious Diseases, vol.61(5), pp. 393-396, 2008.

[28] I.M.I. Moussa, S.A. Kabli, H.A. Hemeg, S.M. Garni and A.M. Shibl, "A novel multiplex PCR for molecular characterization of Methicillin resistant Staphylococcus aureus recovered from Jeddah, Kingdom of Saudi Arab,” Indian Journal of Medical Microbiology, vol. 30(3), pp. 296-301, 2012.

[29] N. D'Souza, C. Rodrigues, and A. Mehta, "Molecular Characterization of Methicillin-Resistant Staphylococcus aureus with Emergence of Epidemic Clones of Sequence Type (ST) 22 and ST 772 in Mumbai, India," Journal of Clinical Microbiology, vol.48(5), pp. 1806-1811, 2010.

[30] M.R. Angel, V. Balaji, J.A.J. Prakash, K.N. Brahmadathan, and M.S. Mathews, Prevalence of inducible Clindamycin resistance in gram positive organisms in a tertiary care centre," Indian Journal of Medical Microbiology, vol.26, pp. 262-264, 2008.

[31] G. B. Shantala, A. S. Shetty, R. Rao, K. Vasudeva, and T. Nagarathnamma, "Detection of inducible Clindamycin resistance in clinical isolates of Staphylococcus aureus by the Disc Diffusion Induction Test," Journal of Clinical and Diagnostic Research, vol. 5(1), pp. 35-37, 2011.

[32] R. Gadepalli, B. Dhawan and S. Mohanthy, "Inducible clindamycin resistance in clinical isolates of Staphylococcus aureus," Indian J Med Res, vol. 123, pp.571-573, 2006. 
[33] K. Date, M. Choudhary and V. Thombare, "Inducible Clindamycin resistance in clinical isolates of staphylococci in a rural hospital," International Journal of Biological and Medical Research, vol.3(3),pp. 1922-1925, 2012.

[34] J.N. Urmi, S. Mulla, L. Shaha and P. Tanvi, "Detection of inducible Clindamycin resistance by an automated system in a tertiary care hospital," African Journal of Microbiology Research, vol. 5(18), pp.2870-2872, 2011.

[35] S. Sanchez, R Mato, H.D. De lencastre, A. Tomaz, "Patterns of multidrug resistance among Methicillin resistant hospital isolates of coagulase positive and coagulase negative staphylococci collected in the international multicenter study resistance in 1997 and 1998," Microbial drug resistance, vol. 6, pp.199$211,2000$.

[36] J.A. Lim, A.R. Kwon, S.K. Kim, Y. Chong, K. Lee, and E.C. Choi, "Prevalence of resistance to macrolide, lincosamide and streptogramin antibiotics in Grampositive cocci isolated in a Korean hospital," Journal of Antimicrobiology and Chemotherapy, vol.49, pp. 489-495, 2002.

[37] P. Wilson, J.A. Andrews, Charlesworth, R.. Walesby, M.. Singer, D.J. Farrell and M. Robbins, "Linezolid resistance in clinical isolates of Staphylococcus aureus," Journal of Antimicrobial Chemotherapy, vol. 51, pp.186-188, 2003.

[38] S.L. Kaplan, "Community-acquired Methicillin-resistant Staphylococcus aureus infections in children, Seminars in Pediatrics Infections Diseases, vol. 17, pp.113-119, 2006.

[39] G.K. Siberry, T. Tekle, K. Carroll and J. Dick, "Failure of Clindamycin treatment of Methicillin-resistant Staphylococcus aureus expressing inducible Clindamycin resistance in vitro," Clinical Infectious Diseases, vol. 37, pp.1257-1260, 2003.

[40] C. Daurel, C. Huet, A. Dhalluin, M. Bes, J. Etienne and R. Leclercq, "Differences in potential for selection of Clindamycin-resistant mutants between inducible erm(A) and erm(C) Staphylococcus aureus genes," Journal of Clinical Microbiology, vol.46, pp.546-550,2008.

[41] D. Jonas, H. Grundmann, D. Hartung, F.D. Daschner and K.J. Towner, "Evaluation of the mecA-fem B Duplex Polymerase Chain Reaction for Detection of Methicillin Resistant Staphylococcus aureus," European Journal of Clinical Microbiology and Infectious Diseases, vol. 18, pp. 643-647, 1999. 